\title{
Control de identidad: Criterios generales para la resolución de casos a la luz de la jurisprudencia reciente de la Corte Suprema de Chile
}

\author{
Identity check: general criteria for the resolution of cases in the light of recent \\ jurisprudence of the Supreme Court of Chile
}

\author{
Manuel Rodríguez Vega* \\ Pontificia Universidad Católica de Chile \\ Santiago, Chile
}

RESUMEN: Este artículo revisa y sistematiza criterios generales desarrollados por la Corte Suprema de Chile que servirán para examinar casos concretos donde se cuestione la legalidad de un control de identidad del artículo 85 del Código Procesal Penal, criterios expresados en fallos que tratan hechos perpetrados con posterioridad a la entrada en vigencia de la Ley $\mathrm{N}^{\circ} 20.931$ de 5 de julio de 2016 que modifica dicho precepto, dictados hasta el mes de junio del año 2019, en particular, se aborda la naturaleza e interpretación de las causales habilitantes del control de identidad, los límites y características del análisis que el órgano jurisdiccional realiza del control de identidad y los criterios generales para determinar la existencia de un indicio habilitante para el control de identidad.

PALABRAS CLAVE: Control de identidad; Jurisprudencia; Corte Suprema de Chile.

ABSTRACT: This article reviews and systematizes general criteria developed by the Supreme Court of Chile that will serve to examine specific cases where the legality of an identity check of Article 85 of the Criminal Procedure Code is questioned, criteria expressed in decisions that concern with acts perpetrated after the enactment of Law No. 20,931 of July 5, 2016, which modifies said provision, issued until June 2019, in particular, addresses the nature and interpretation of the enabling causes of identity control, limits and characteristics of the analysis carried out by the court of identity check and the general criteria to determine the existence of an enabling indicator for identity check

KEYWORDS: Identity check; Jurisprudence; Supreme Court of Chile

\section{INTRODUCCIÓN}

Hoy en día el control de identidad del artículo 85 del Código Procesal Penal ${ }^{1}$ (en adelante $\mathrm{CPP}$ ) se ha erigido como una herramienta de recurrente uso por las policías, a través de la

\footnotetext{
* Doctor en Derecho, Universidad de Chile. Magíster en Derecho Penal, Universidad de Talca. Licenciado en Ciencias Jurídicas y Sociales, Pontificia Universidad Católica de Chile. Profesor Asistente Adjunto, Departamento Derecho Procesal, Facultad de Derecho, Pontificia Universidad Católica de Chile. Dirección postal: Av. Libertador Bernardo O’Higgins N³40, Santiago. Correo electrónico: merodrig@uc.cl

Artículo recibido el 28 de junio de 2019 y aceptado para publicación el 1 de octubre de 2019

${ }^{1}$ Art. $85 \mathrm{CPP}$ incisos $1^{\circ}$ y $2^{\circ}$ : "Los funcionarios policiales señalados en el artículo 83 deberán, además, sin orden previa de los fiscales, solicitar la identificación de cualquier persona en los casos fundados, en que, según las circunstancias, estimaren que exista algún indicio de que ella hubiere cometido o intentado cometer un crimen, simple delito o falta; de que se dispusiere a cometerlo; de que pudiere suministrar
} 
cual obtienen evidencia esencial para vincular a una persona con un delito determinado cometido momentos antes o cuya perpetración se descubre durante el mismo control de identidad al hallar al controlado con objetos cuya posesión o tenencia en determinadas circunstancias la ley sanciona penalmente, como lo es el porte de elementos cortantes o punzantes, de armas de fuego o de drogas o estupefacientes ${ }^{2}$.

Tal recurrencia trae naturalmente aparejado que los Tribunales con competencia en lo penal, Juzgado de Garantía (en adelante JG) y Tribunal de Juicio Oral en lo Penal (en adelante TJOP), continuamente se pronuncien en los distintos procedimientos sobre la legalidad de dichas actuaciones policiales, al resolver los cuestionamientos que las defensas de los imputados plantean y, consecuencialmente, la CS conoce frecuentemente de recursos de nulidad presentados por los apoderados de aquellos condenados sometidos a control de identidad cuyos reclamos no fueron acogidos por los órganos jurisdiccionales de la instancia.

Pues bien, las múltiples y diversas situaciones que pueden dar origen a un control de identidad y que son conocidas por los tribunales dificulta construir una jurisprudencia uniforme en el tratamiento y resolución de los distintos casos, óbice al que se suma la misma vaguedad de los conceptos de que se vale el ya citado artículo 85 para definir los supuestos en que las policías se encontrarán habilitadas para controlar la identidad de una persona determinada, esto es, cuando se presente un "indicio de que ella hubiere cometido o intentado cometer un crimen, simple delito o falta; de que se dispusiere a cometerlo; de que pudiere suministrar informaciones útiles para la indagación de un crimen, simple delito o falta; o en el caso de la persona que se encapuche o emboce para ocultar, dificultar o disimular su identidad”.

Esta conjunción de elementos parece aconsejar, antes del estudio y sistematización de la casuística que constantemente se verá sobrepasada por la cambiante realidad, abocarse al examen y ordenamiento de algunos criterios o estándares generales que los tribunales han asentado como rectores y orientadores de la resolución de casos concretos y, en especial, los forjados o delineados por la Corte Suprema (en adelante CS) atendido que ella tiene la última palabra sobre las vulneraciones cometidas por los agentes de la policía al someter una persona a un control de identidad sin presentarse los requisitos legales para ello, hecho el reclamo en distintas etapas del procedimiento seguido ante los JG y TJOP y fracasada la alegación, al constituir dicha inobservancia una infracción a derechos fundamentales, como la libertad personal, privacidad o el debido proceso, lo que se encuadra en la causal de nulidad del artículo 373 a) CPP, de competencia de dicha jurisdicción conforme al inciso $1^{\circ}$ del artículo 376 del mismo texto.

informaciones útiles para la indagación de un crimen, simple delito o falta; o en el caso de la persona que se encapuche o emboce para ocultar, dificultar o disimular su identidad. El funcionario policial deberá otorgar a la persona facilidades para encontrar y exhibir estos instrumentos.

Procederá también tal solicitud cuando los funcionarios policiales tengan algún antecedente que les permita inferir que una determinada persona tiene alguna orden de detención pendiente".

${ }^{2}$ Sobre la historia de la regulación del control de identidad, vid. RABI GonZÁlez (2010) p. 325 e IRARRÁZABAL (2015) p. 236. 
En ese orden entonces, analizo lo dicho por la CS al fallar recursos de nulidad invocándose la causal de la letra a) del artículo 373 CPP y regido el hecho que origina el control de identidad por la Ley $\mathrm{N}^{\circ}$ 20.931, que "facilita la aplicación efectiva de las penas establecidas para los delitos de robo, hurto y receptación y mejora la persecución penal en dichos delitos" (DO 05/07/2016), ya que modificó diversos aspectos relevantes de la actuación en comento y, principalmente, parece intentar reducir las exigencias para llevarla a cabo al cambiar el requisito de "indicios" por "algún indicio", variación legal que ha sido recepcionada por nuestra jurisprudencia, en particular por la CS, la que en sus sentencias reflexiona sobre las incidencias de ello.

Este estudio trata de la naturaleza e interpretación de las causales habilitantes del control identidad, de los límites y características del análisis que el órgano jurisdiccional realiza de tal control y de los criterios generales para determinar existir un indicio que faculta ejecutarlo, y abordo subtemas dentro de cada uno de estos tópicos.

\section{NATURALEZA E INTERPRETACIÓN DE LAS CAUSALES HABILITANTES DEL CONTROL IDENTIDAD}

\section{A través del control de identidad la policía cumple su rol en la prevención de la comisión de delitos como de auxiliar de la investigación}

El máximo Tribunal ha explicado que con el control de identidad las policías materializan su rol preventivo como auxiliar del Ministerio Público (en adelante MP) en la investigación de hechos delictivos y al efecto, en MP c/Llancaleo (2017): 21 diciembre 2017, rol $\mathrm{n}^{\circ}$ 37.208-17, ha expresado

"que [...] Carabineros de Chile tiene dos funciones: una, la prevención de la comisión de delitos en resguardo del orden público y la seguridad pública interior, y la otra le otorga el carácter de organismo auxiliar del Ministerio Público en la investigación de delitos. El control de identidad comprende ambos componentes de la actividad policial, pues, por una parte usualmente esta diligencia sólo importa acciones de prevención, de las que pueden derivar 'indicios' que obligan a la Policía a reaccionar ante la probable comisión de un ilícito mediante acciones autónomas de investigación” ${ }^{3}$.

De esta diferenciación se advierte que entre los hechos o circunstancias respecto de las cuales debe existir algún indicio conforme al artículo $85 \mathrm{CPP}$ algunos dan cuenta que el control de identidad permitirá a la policía ejercer su labor preventive y otros facilitarán su labor de auxiliar en la investigación ${ }^{4}$.

\footnotetext{
${ }^{3}$ En el mismo sentido la CS en MP c/Rojas (2018, rol n ${ }^{\circ}$ 6.345-18), MP c/Marambio (2018, rol $\mathrm{n}^{\circ}$ 7.575-18), MP c/Igor (2018, rol ${ }^{\circ}$ 8.258-18), MP c/Villanueva (2018, rol $\mathrm{n}^{\circ}$ 26.724-18), MP c/Burgos (2019, rol $^{\circ}$ 28.309-18), MP c/Araos (2019, rol n 4.271-19) y MP c/Rojas (2019, rol n 32.699-18). RABI GonZÁLEZ (2010) p. 335, concordantemente, postula que solo resulta razonable exigirle a una persona "que se identifique, en el marco del rol general que les corresponde a las policías, en particular desarrollando su función preventiva, como también en el papel de auxiliar al Ministerio Público en tareas de investigación y persecución penal, consagrado en el artículo 79 CPP".

${ }^{4}$ Sobre el rol de la policía en la investigación preliminar, vid. DUCE y RIEGO (2009) p. 141.
} 
Así, si el indicio apunta que la persona "hubiere cometido o intentado cometer un crimen, simple delito o falta", es decir, que el ilícito fue consumado o al menos alcanzó un grado de desarrollo imperfecto sancionado penalmente, sea tentativa o frustración, o que esa persona "pudiere suministrar informaciones útiles para la indagación de un crimen, simple delito o falta", con el control de identidad se buscará identificar al autor, cómplice o encubridor del delito ya cometido o intentado, u obtener información que permita ese objeto o recabar otra información para esclarecer su forma de comisión ${ }^{5}$.

Aunque la norma habla de indicio del que hubiere "cometido" o "intentado cometer" un delito, lo que podría llevar a sostener que solo podría controlarse la identidad de quien existe indicio de ser autor ejecutor del ilícito, excluyendo las otras formas de autoría que comprende el artículo 15 del Código Penal (en adelante CP) y la complicidad y el encubrimiento contemplados en los artículos 16 y 17 del mismo código, respectivamente, lo sustancial aquí es que todos son susceptibles de un control de identidad porque podrían "suministrar informaciones útiles para la indagación de un crimen, simple delito o falta", precisamente dada esa calidad de cómplices o encubridores.

Asimismo, en estos supuestos, en los que el delito se ha ejecutado, cualquiera sea su grado de desarrollo, no se está en una situación de flagrancia regulada por el artículo 130 CPP y, por ende, no cabe exigir para realizar el control de identidad que la autoría o participación de la persona controlada se exteriorice en alguna de las formas que enuncia el citado precepto o de una manera manifiesta y patente análoga pues para la actuación en estudio solo se requiere algún "indicio", esto es, que haya un hecho objetivo que permita "inferir" esa participación, la cual no es concluyente ni evidente del modo que lo es en una situación de flagrancia ${ }^{6}$. De presentarse esta última, desde luego, los policías actuarán facultados por el estatuto pertinente a la detención y no por el artículo $85 \mathrm{CPP}$, aun cuando los agentes crean equivocadamente actuar al amparo de éste y no de aquél, lo que no es infrecuente.

Por otra parte, si bien el control de identidad los policías deben realizarlo sin necesidad de instrucción del $\mathrm{MP}^{7}$ acierta la CS al catalogarlo como una actuación que evidencia el

\footnotetext{
${ }^{5}$ RABI GONZÁleZ (2010) p. 334 destaca que el control de identidad "está orientado a que los agentes de la policía exijan la identificación de una persona, sólo en cuanto tal actividad es un mecanismo orientado a materializar fines propios de la investigación y persecución penal, con amplio alcance. Esto es, identificar partícipes en hechos punibles, determinar su participación específica en los mismos, vincularlos a la investigación mediante medidas restrictivas o privativas de libertad, conseguir evidencia e incluso obtener información de testigos o terceros sin vinculación personal a hecho delictual alguno y, en suma, poder desarrollar, a través de los procedimientos específicos que el control de identidad supone (registro de vestimentas, de vehículo, consulta de órdenes de detención, etc.) estrategias de persecución penal de alcance general o especial (lugares o sectores específicos, tipos de delitos, etc.)".

${ }^{6}$ RABI GonZÁlez (2010) p. 349, asume como concepto de indicio, en el marco del procedimiento penal, "una circunstancia de hecho conocida, que permite conocer o inferir la existencia de otro no percibido" y este último -agrega el autor- lo precisa de manera específica el artículo 85 CPP.

${ }^{7}$ Resalta este aspecto la CS, MP c/Correa (2018, rol n ${ }^{\circ}$ 5.353-18), al explicar que "la diligencia de control de identidad reglada en el artículo 85 del Código Procesal Penal es una actuación autónoma que, por ende, pueden realizar las policías sin necesidad de instrucción del Ministerio Público, de manera que el alegado incumplimiento del deber de informarle a dicho organismo, conforme al artículo 84 del mismo código, de la denuncia anónima recibida que motivó dicho control, en nada altera la procedencia y validez de dicha actuación, la que, incluso de haberse puesto en conocimiento del Fiscal, igualmente podría haberse
} 
carácter de "organismo auxiliar del Ministerio Público en la investigación de delitos" pues, en último término, el resultado de esta diligencia servirá a la indagación conducida exclusivamente por ese ente persecutor y por lo cual puede, conforme al artículo $87 \mathrm{CPP}$, dictar instrucciones generales para orientar y ordenar su ejecución.

Respecto de aquel contra quien exista algún indicio "de que se dispusiere" a cometer un crimen, simple delito o falta debe entenderse -por oposición a los casos ya vistos- que se trata de un individuo que no ha dado principio de ejecución al delito pero hay elementos que indican que se prepara o dispone a cometerlo -actos preparatorios en general no punibles según prescribe el artículo $8 \mathrm{CP}$-, situación en que claramente la policía estará materializando una labor preventiva para evitar que ese posible delito se concrete, mas un uso exagerado e inadecuado de esta hipótesis en particular podría avalar las protestas de los que afirman que el control de identidad es una forma encubierta de detención por sospecha, por lo que resulta aún más relevante y urgente resaltar las limitaciones y estándares forjados por la CS en su jurisprudencia y que más adelante compendio.

Ante una persona que "se encapuche o emboce para ocultar, dificultar o disimular su identidad" la policía podría estar actuando en cumplimiento de ambas funciones, preventivas o de investigación, según el contexto concreto al que se enfrente, pues el encapucharse o embozarse podría ser el medio con el que busca evitar ser identificado quien ha cometido un delito o se dispone o prepara para cometerlo.

Finalmente, en cuanto a quien "los funcionarios policiales tengan algún antecedente que les permita inferir que una determinada persona tiene alguna orden de detención pendiente", a diferencia de lo ya visto, el control de identidad constituye una medida que facilita la labor de la policía, ahora como auxiliar de la administración de justicia.

\section{Causales habilitantes del control de identidad deben interpretarse restrictivamente}

Dado que la investigación a través de medios y la fuerza pública la dirige exclusivamente el MP (arts. 83 Constitución Política, 180 CPP y 1 Ley Orgánica Constitucional del MP), las policías sólo cumplen una función auxiliar de esa labor y no de co-dirección y, por ende, las normas que excepcionalmente las facultan realizar actuaciones investigativas y que importan afectar derechos fundamentales de las personas, como su libertad ambulatoria y privacidad, cual sucede con la diligencia de control de identidad, deben, sobre todo a la luz del inciso 2 del artículo $5 \mathrm{CPP}^{8}$, ser interpretadas restrictivamente, teniendo el agente policial que supeditarse y ajustar estrictamente a la causal habilitante invocada sin poder argüir situaciones análogas o similares, tanto en su descripción como en su gravedad, a las previstas por el legislador, limitación que desde luego ha de considerar el órgano jurisdiccional competente al dirimir la legalidad o ilegalidad de la actuación.

ejecutado sin siquiera darle noticia, de concurrir los presupuestos para ello, pues no debe olvidarse que el citado artículo 85 establece el 'deber' de realizarla en ese caso".

8 "Las disposiciones de este Código que autorizan la restricción de la libertad o de otros derechos del imputado o del ejercicio de alguna de sus facultades serán interpretadas restrictivamente y no se podrán aplicar por analogía". 
En razón de lo expuesto, con la Ley $\mathrm{N}^{\circ} 20.253$-de 14 de marzo de 2008-que modificó el artículo $85 \mathrm{CPP}$, que establecía procedente el control de identidad en "casos fundados, tales como [...]" mencionando luego ejemplos de ello, y reemplazó la redacción anterior por "los casos fundados, en que, según las circunstancias", creo, a diferencia de RABI GONZÁLEZ9", que el texto se refiere hoy a la totalidad de las hipótesis que son constitutivas de un "caso fundado" que autoriza para controlar la identidad de una persona ${ }^{10}$ y no se trata, a contrario sensu, de meras hipótesis ilustrativas ${ }^{11}$.

En ese orden, la CS, MP c/Villarreal (2017): 13 septiembre 2017, rol n 36.237-17, declaró

"que la regla general de la actuación de la policía es que debe realizarse bajo las órdenes o instrucciones del Ministerio Público y como excepción, su desempeño autónomo en la ejecución de pesquisas y detenciones en precisos y determinados casos delimitados claramente por el legislador, que incluso ha precisado un límite temporal para su vertiente más gravosa (las detenciones) con el objeto de eliminar o reducir al máximo la discrecionalidad en el actuar policial del que se derive restricción de derechos[...]. [...], este tribunal ha señalado reiteradamente que dicha regulación trata, entonces, de conciliar una efectiva persecución y pesquisa de los delitos con los derechos y garantías de los ciudadanos, estableciéndose en forma general la actuación subordinada de los entes encargados de la ejecución material de las órdenes de indagación y aseguramiento de evidencias y sujetos de investigación al órgano encargado por ley de la referida tarea, los que a su vez actúan conforme a un estatuto no menos regulado [...] en lo referido a las medidas que afecten los derechos constitucionalmente protegidos de los ciudadanos [...]. De su tenor, entonces, aparece evidente que en cuanto se trata de normativa de excepción, estricta y precisa por la naturaleza de los derechos afectados en su consagración, su interpretación debe sujetarse a parámetros semejantes de restricción"12.

Complementando lo anterior, la CS, en MP c/Llancaleo (2017): 21 diciembre 2017, rol $\mathrm{n}^{\circ}$ 37.208-17, ha dicho que

"tanto los principios y directrices generales del proceso penal como la regulación específica del control de identidad llevan inequívocamente a darle un sentido limitado a tal actuación, [...] e, por afectar o poder afectar garantías constitucionales de los ciudadanos, [...], por tener un objetivo preciso, como es

\footnotetext{
${ }^{9}$ RABi GonZÁLEZ (2010) p. 337.

${ }^{10}$ El MP en su Manual de Primeras Diligencias de septiembre de 2017, p. 20, indica que "Constituye una obligación para el personal policial practicar el control de identidad de una o más personas, en los casos fundados que establece el artículo 85 Código Procesal Penal" (Manual disponible en: http://www.fiscaliadechile.cl/Fiscalia/archivo?id=31695\&pid=211\&tid=1\&d=1, fecha de consulta: 7 de junio de 2019).

${ }^{11}$ Para evitar reiteraciones innecesarias, aquí aludo a esas hipótesis taxativas, de manera general, como indicio o indicios de actividad delictiva.

${ }^{12}$ También la CS en MP c/Valencia (2017, rol no 36.630-17), MP c/Sepúlveda (2018, rol no 22.000-18), MP c/Pacheco (2018, rol n ${ }^{\circ}$ 24.659-18), MP c/Miranda (2018, rol n 26.422-18), MP c/Márquez (2019, rol nº 1.502-19), MP c/Mejías (2019, rol n 2.488-19) y MP c/Muñoz (2019, rol n 7.756-19).
} 
obtener la identidad de los sujetos que se encuentran en la situación prevista en la norma. En ese entendido, y teniendo en consideración que se trata de una facultad autónoma de la policía, resulta claro que puede llevarse a cabo solamente cuando se presentan las precisas circunstancias contenidas en el texto legal ya citado"13.

\section{Exigencia de "algún indicio", en vez de "indicios", no importa una mengua en la protección de los derechos constitucionales afectados por el control de identidad}

Al entender la CS que el control de identidad afecta derechos fundamentales de las personas, sin embargo que en algunos supuestos se justifica en que la policía cumple sus funciones preventivas e investigativas asignadas por ley, se ha señalado que la modificación de la Ley $\mathrm{N}^{\circ} 20.931$ al artículo $85 \mathrm{CPP}$ al sustituir el vocablo "indicios" por la expresión "algún indicio" no supone brindar una menor protección a esos derechos sino solo una mirada distinta al analizar las circunstancias fundantes de la actuación, de manera que no hay que detenerse en observar su número -si es singular o plural- sino que centrarse en la gravedad y fuerza del indicio que justifique limitar la libertad ambulatoria del controlado así como su privacidad por el consiguiente o paralelo registro, todo ello en aplicación del principio de proporcionalidad que debe regir tales actuaciones y que se entiende como uno que "examina la relación existente entre una medida de la autoridad, adoptada en el ámbito de sus facultades discrecionales, gravosa para sus destinatarios, y la finalidad perseguida por esa medida" ${ }^{\prime 4}$.

De ese modo, sobre la sustitución de la exigencia de "indicios" por "algún indicio" la CS, en MP c/Cifuentes (2017): 22 junio 2017, rol n 19.113-17, explicó que

"al contrario de lo que en una primera lectura podría considerarse, no conlleva necesariamente un retroceso en la protección y garantía de la libertad personal que asegura el artículo $19 N^{\circ} 7$ de la Constitución [...], desde que su objeto no debe entenderse como una disminución de los requisitos necesarios para la procedencia del control de identidad, sino sólo como un cambio de enfoque en relación a los aspectos o elementos a que deberá darse prioridad en la determinación de su procedencia. [...], la ley transita de un enfoque que podría denominarse 'aritmético', requiriendo sólo una pluralidad de indicios, con independencia de la gravedad o precariedad de éstos, a otro que podría calificarse como 'sustantivo', en el que debe atenderse prioritariamente más bien a la aptitud, entidad y objetividad de los hechos y circunstancias conocidos o de que se da noticia a los policías, para dilucidar si se trata o no de un indicio de que la persona a fiscalizar 'hubiere cometido o intentado cometer un crimen, simple delito o falta o de que se dispusiere a cometerlo' -o se encuentre en alguno de los otros supuestos que trata la norma-, con

\footnotetext{
${ }^{13}$ En el mismo sentido la CS en MP c/Rojas (2018, rol n ${ }^{\circ}$ 6.345-18), MP c/Marambio (2018, rol $\mathrm{n}^{\circ}$ 7.575-18), MP c/Igor (2018, rol $\mathrm{n}^{\circ}$ 8.258-18), MP c/Villanueva (2018, rol $\mathrm{n}^{\circ}$ 26.724-18), MP c/Burgos $\left(2019\right.$, rol $\mathrm{n}^{\circ}$ 28.309-18), MP c/Rojas (2019, rol n³2.699-18) y MP c/Araos (2019, rol n 4.271-19).

14 AldunAte (2008) p. 264. Sobre el principio de proporcionalidad, tratado en relación a las medidas cautelares, vid. Horvitz LENNON y LóPEZ MASLE (2003) pp. 353-354 y DuCE y RIEGO (2009) p. 266.
} 
abstracción de si esos hechos y circunstancias constituyen uno o varios indicios, sino únicamente a si los mismos justifican razonablemente la temporal restricción de la libertad personal de quien es sometido al control, de modo que con ello se descarte el uso arbitrario, antojadizo o discriminatorio de esta herramienta legal contra un sector de la población. Si se reemplazó 'indicios' (pluralidad) por 'indicio', quiere decir que el singular y único deberá poseer la necesaria vehemencia y fuerza que sustituya a la antigua pluralidad. De esa manera -como se suele señalar en relación a la valoración de la prueba testimonial-, ahora los indicios se pesan y no se cuentan para determinar si se cumple el presupuesto legal de encontrarse ante un 'caso fundado', extremo medular que se mantiene después de la Ley $N^{\circ} 20.931$ para habilitar la realización de un control de identidad".

Con esta interpretación de la indicada modificación legal, a juicio de la CS "se logra compatibilizar el claro y conocido objetivo de la citada reforma de eliminar trabas innecesarias a la oportuna y eficiente labor policial y, por otra parte, se conserva la adecuada protección de la libertad personal de los ciudadanos reconocida en el artículo $19 N^{\circ} 7$ de la Constitución Política de la República"15.

\section{Indicios deben sostenerse en circunstancias objetivas y comprobables}

Siempre en línea con las restricciones que ha delineando, la CS, en MP c/Miranda (2018): 6 diciembre 2018, rol $\mathrm{n}^{\circ}$ 26.422-18, resolvió que el artículo 85 CPP

"supone que la habilitación policial ha de fundarse en elementos objetivos que permitan el control de identidad y las actuaciones que le son propias, es decir, no se trata de una mera subjetividad o intencionalidad que crea ver el policía, validando de esa forma cualquier elemento como indicio, por ejemplo, antecedentes policiales, estilo de vestimenta, rango etario, sector social, sino que lo exigible es la presencia de circunstancias objetivas y comprobables que den sustento y seriedad a la intervención policial" $"$.

\footnotetext{
${ }^{15}$ Desarrolla el mismo fundamento la CS en MP c/Murillo (2018, rol no 26.194-18) y MP c/Torres (2019, rol $\mathrm{n}^{\circ}$ 2.222-19). La CS, en MP c/Muñoz Quilempan (2018, rol n 8.255-18), sintetiza esas ideas: "La modificación introducida al artículo 85 del Código Procesal Penal sustituyó la expresión 'indicios' por ‘indicio' por lo que este antecedente singular deberá revestir la necesaria entidad y vehemencia para poder ser equiparado a la pluralidad que antes se requería, lo que no sucede en este caso". La CS, en MP c/González Girón (2019, rol n 5.419-19) y MP c/Dorado (2019, rol n 9.773-19), recuerda que "la Ley 20.931 rebajó el estándar del artículo 85 del Código Procesal Penal, al disponer que para proceder al control de identidad exige que 'exista algún indicio',".

${ }^{16}$ Este extracto lo repite la CS en MP c/Mejías (2019, rol no 2.488-19) e igual aspecto lo trata en $M P c / P a v e z$ (2017, rol n' 15.472-17) al señalar que "el control de identidad, al ser una diligencia que afecta las garantías constitucionales de los ciudadanos, no puede fundarse en apreciaciones subjetivas o interpretaciones de los policías respecto de las motivaciones que habría detrás de las acciones que presentan los individuos, sino que debe sostenerse en circunstancias objetivas y verificables, puesto que sólo de esa manera es posible dotar de validez, a luz de los derechos de los justiciables, a una actuación de carácter excepcional como la de la especie".

La CS en MP c/Murillo (2018, rol no 26.194-18) manifiesta que "el elemento indiciario empleado por los funcionarios policiales en el caso de marras, [...] no da cuenta de ningún elemento objetivo del cual pueda desprenderse algún indicio de que el acusado y su acompañante intentaban o se disponían a cometer un
} 
De esta decisión se colige que las circunstancias fundantes del control de identidad son señales o "pistas" que a cualquier persona sensata, libre de prejuicios y de conocimiento previo del individuo afectado, le llevarían a inferir que éste cometió o dispone a cometer un delito, excluyéndose de ese modo incluso como elemento a ponderar el tratarse de alguien que reiteradamente ha perpetrado un mismo tipo de ilícitos y que es avistado en un sector en el que ellos suelen cometerse, por ejemplo, advertir a un sujeto detenido en numerosas ocasiones por robo en lugar habitado merodeando por un sector en el cual no reside ${ }^{17}$.

\section{LÍMITES Y CARACTERÍSTICAS DEL ANÁLISIS QUE EL ÓRGANO JURISDICCIONAL REALIZA DEL CONTROL DE IDENTIDAD}

Atendida la complejidad de la revisión de circunstancias pasadas que tienen en cuenta los policías para realizar un control de identidad, en situaciones, por lo general, espontáneas e intempestivas y que demandan, por tanto, reacciones y respuestas inmediatas, la CS ha ido sistematizando, pero también acotando, el alcance del examen de legalidad del control de identidad que pueden realizar los jueces, el que se se produce en varios momentos a lo largo del procedimiento ordinario, siendo el primero, habitualmente, el efectuado por el JG al revisar la legalidad de la detención derivada de dicho control en la primera audiencia del artículo $132 \mathrm{CPP}^{18}$, seguido por las discusiones planteadas en la audiencia de preparación de juicio oral y en este, para excluir, o no valorar o valorar negativamente, respectivamente, los elementos probatorios derivados del control de identidad que se postula como ilegal.

Aquí me concentro en el análisis de legalidad que realiza la CS al conocer los recursos de nulidad deducidos por la causal de la letra a) del artículo 373 CPP y en los cuales se cuestiona la diligencia en comento por vulnerar garantías fundamentales, principalmente el debido proceso y los derechos a la libertad personal y la privacidad y, consecuencialmente, se afirma que los elementos probatorios derivados de ella, directa o indirectamente, no pueden servir de sustento a la decisión condenatoria impugnada.

\section{Al resolver un recurso de nulidad la CS debe estarse a los hechos fijados por el Tribunal de la instancia}

delito, sino sólo de la impresión o interpretación que hace un policía de su percepción olfativa que, huelga señalar, podría responder a múltiples justificaciones o razones diversas a la comisión de un ilícito. En este orden de ideas, se condice con una afirmación del todo subjetiva, no verificable y, por lo mismo, al margen de los rigurosos extremos de la norma ya citada, por cuanto una actuación autónoma e intrusiva como el control de identidad debe, necesariamente y dado que afecta garantías constitucionales como el derecho a la intimidad, basarse en un indicio de carácter objetivo y por ello susceptible de ser objeto de revisión judicial. Como ya lo ha resuelto esta Corte, el solo hecho de percibir olor a marihuana no satisface la exigencia de un signo ostensible del tráfico de drogas (SCS Rol 21.413-14, de 22 de septiembre de 2014)". Mismo razonamiento observa la CS en $M P$ c/Torres (2019, rol no 2.222-19).

${ }^{17}$ El MP, en su Manual de Primeras Diligencias, p. 21, instruye a los policías ser objetivos en este ámbito de actuación, al señalar que si hay indicio de que la persona a controlar hubiera cometido, intentado cometer o se dispusiera a cometer un crimen, un simple delito o una falta "El personal policial debe ceñirse a ciertos parámetros objetivos al momento de practicar un control de identidad, tales como las circunstancias, accidentes, actitudes o conductas que, en el caso concreto, rodean al sujeto sometido a control" (Manual disponible en: http://www.fiscaliadechile.cl/Fiscalia/archivo?id=31695\&pid=211\&tid=1\&d=1, fecha de consulta: 7 de junio de 2019).

${ }^{18}$ Sobre el control de legalidad de la detención y actos previos a ésta, como el control de identidad, vid. FALCONE SALAS (2012) p. 479. 
Hoy parece existir consenso en Tribunales de Juicio Oral en lo Penal, como lo demuestra el que sin mayor controversia se aboquen a esta discusión, así como en la $\mathrm{CS}^{19}$, que la legalidad de la diligencia de control de detención y la licitud de los elementos probatorios derivados de ella puede ser discutida en el juicio oral, amén de las audiencia de preparación de juicio oral. Es más, alegarla en esa instancia de juicio parece ser una exigencia de admisibilidad del recurso de nulidad conforme al artículo $377 \mathrm{CPP}$, que requiere para ello haber "reclamado oportunamente del vicio o defecto" 20 .

Lo anterior conlleva que la alegación de ilegalidad del control de identidad por la falta del indicio que habilita a los policías para llevarlo a cabo, formulada en el juicio oral, importa en esa instancia rendir prueba para dilucidar el punto, particularmente mediante el interrogatorio y contraexamen de los agentes que lo llevaron a cabo. De ese modo, el contexto situacional que da lugar al señalado control es un asunto controvertido en el juicio y materia de prueba por las partes, probanzas que luego son valoradas por los jueces, los que forman su convicción sobre la dinámica de esos hechos.

Sin embargo, habitualmente en el libelo en que se formula el recurso de nulidad de la defensa del condenado se ofrece -conforme al art. 359 CPP-, como medios de prueba para acreditar las circunstancias que constituyen la causal invocada, el registro de audio de las declaraciones prestadas en el juicio oral por los policías que ejecutaron el control de identidad, o se alude a las transcripciones que de ellas se efectúa en la sentencia que dicta el Tribunal de la instancia (TJOP o JG), o al contenido del parte policial, buscando con ello que la CS, al dirimir la legalidad del control de identidad dubitado, tenga por cierto un escenario fáctico diverso al que fijaron los magistrados del grado.

${ }^{19}$ La CS, en MP c/Ramírez (2018, rol n 44.457-17), declara que “[...], en La 'exclusión de la prueba ilícita en el nuevo proceso penal chileno', 'de las diversas posiciones [...] hay al menos una que no parece admisible desde un punto de vista material, como es la de entender que el tribunal de juicio oral se encuentra absolutamente atado por el auto de apertura en términos tales que no sólo está obligado a recibir la prueba ilícita sino que también a valorarla y eventualmente a dictar sentencia con fundamento en ella, haciendo total abstracción de una ilicitud que no le corresponde a él declarar. [...], es indudable que el art. 276 cumple [...] la función de una prohibición general de valoración de la prueba obtenida con infracción de garantías fundamentales, prohibición que rige también y de modo especial para el tribunal que precisamente está llamado a valorar la prueba [...]'. '[...] cuando el mecanismo óptimo destinado a impedir la valoración de la prueba ilícita fracasa, subsiste pese a ello incólume la prohibición de hacerlo. Es lo que inequívocamente se desprende de [...] la historia fidedigna de la ley, cuando el legislador declara [...] estar estableciendo un sistema que 'evita que el tribunal oral tome conocimiento de estas pruebas y se forme un juicio con elementos que no podrá después valorar' [...]. Es indudable que esta situación no es ideal y [...] hubiese sido preferible que hubiese funcionado el mecanismo previsto por la ley para evitar no sólo la contaminación sino que también que se renovara una y otra vez la discusión sobre el material probatorio a presentar en juicio; pero cuando no es ése el caso sólo cabe procurar alcanzar de la mejor forma posible resultados similares a los perseguidos por la ley. Cualquier otra interpretación implicaría sostener un supuesto deber de los jueces del fondo de fallar conscientemente con fundamento en la vulneración de garantías fundamentales.' [...]. [...], [...] sobre la oportunidad para resolver la exclusión de prueba por ilicitud, [...] 'esta opción del legislador no obsta a que el tribunal oral pueda y deba-como remedio tardío en términos estructurales-excluir en sede de valoración aquella prueba que, indebidamente, haya pasado los filtros de la audiencia de preparación del juicio oral', ya que resulta inadmisible fundar en una prueba contaminada de ilicitud una decisión condenatoria, criterio que [...] ha sido recogido por esta Corte".

${ }^{20}$ Aisladamente y en sentido contrario Corte de Apelaciones (en adelante CAp) de Santiago en MP c/Villarroel (2018, rol n 4.168-18) y Octavo JG de Santiago en MP c/Rañileo (2019, RUC N ${ }^{\circ} 1800614688-7$ y RIT N 4936-2018). Entre los autores, LÓPEZ MASLE (2004) p. 203. 
Ante tales alegaciones, la CS reiteradamente ha desestimado valorar nuevamente esos elementos al conocer un recurso de nulidad $\mathrm{y}$, por ende, rechaza establecer que los hechos se desenvuelven de una manera diversa a la asentada por los magistrados, y solo posibilita rendir prueba para acreditar las circunstancias que constituyen la causal invocada únicamente si la infracción o vicio no fue objeto de prueba en el juicio y por tanto de pronunciamiento del tribunal a quo o se cometió durante la sustanciación del pleito, por ejemplo, un exceso de los jueces al realizar preguntas aclaratorias que evidencia falta de imparcialidad en su cometido ${ }^{21}$ lo que, huelga explicar, no es materia de prueba ni de resolución en la sentencia de modo que, de no aceptarse su comprobación conforme al artículo 359 CPP, el impugnante no podría demostrar la infracción o vicio que arguye.

Al respecto, de manera general, la CS, en MP c/Herrera (2018): 26 marzo 2018, rol $\mathrm{n}^{\circ}$ 2.519-18, declaró que

"Como se advierte de la lectura del fallo [...], las circunstancias en que se produjo el ingreso al inmueble, el hallazgo de las sustancias estupefacientes y especies, en especial el arma de fuego, fueron el meollo de lo discutido en el juicio oral [...], [...] en que la prueba rendida fue sometida al escrutinio de todos los intervinientes así como del tribunal, [...] bajo el respeto de los principios de bilateralidad de la audiencia, oralidad, publicidad e inmediación. Corolario de esta actividad probatoria, los sentenciadores fijaron los hechos ya reproducidos en el basamento tercero, conforme a las normas que rigen la apreciación de la prueba [...]. Derivado de lo anterior es que [...] no pueden desconocerse dichos hechos, asentados por los magistrados del grado, para sustituirlos por aquellos consignados en la declaración del imputado en lo que dice relación al lugar donde efectuaba la transacción de la sustancia estupefaciente, pues ello significaría la posibilidad de transformar el recurso de nulidad en una nueva instancia para discutir los hechos ya fijados por el Tribunal y se instalaría de paso una oportunidad para que la defensa debata nuevamente los presupuestos fácticos establecidos por los sentenciadores de la instancia [...]. Así [...], dado que la jurisprudencia se ha uniformado en entender que el juicio oral constituye una etapa más [...] para discutir y probar la ilicitud de la prueba de cargo, ello trae aparejado que para estimar cumplido el requisito previsto en el artículo 377 del Código Procesal Penal de haber preparado el recurso, dicha ilicitud debe ser reclamada oportunamente en el juicio oral, lo que [...] conlleva [...] que el tribunal de la instancia siempre se habrá pronunciado sobre este asunto y determinado los hechos acreditados o no probados en relación a la alegación de ilicitud, hechos a los que [...], en este particular tipo de casos, deberá estarse esta Corte al resolver el recurso que afinque en la misma materia, en relación a la primera causal invocada" 22 .

\footnotetext{
${ }^{21}$ Así la CS en MP c/Inzunza (2014, rol n 8.644-4).

${ }^{22} \mathrm{La}$ CS, en MP c/González Rincón (2019, rol n 12.166-19), expresó, resumidamente, que "para la decisión respecto de las tres causales en examen, esta Corte razonará sobre la base de los hechos establecidos por los jueces de la instancia en su fallo y ello es así pues allí la prueba rendida se sometió al escrutinio de todos los intervinientes, así como del tribunal, bajo el respeto de los principios de bilateralidad de la audiencia, oralidad, publicidad e inmediación. Como corolario de esta actividad probatoria, los sentenciadores fijaron
} 
2. Al dirimir si se presenta algún indicio deben ponderarse en conjunto todas las circunstancias concurrentes y no examinarse si cada una de éstas, individualmente consideradas, constituye un indicio distinto

Sobre la exigencia de "algún indicio" de actividad delictiva y el examen para verificar si aquél se da o no en la situación que enfrenta el policía, la CS ha aclarado que el análisis se lleva a cabo abarcando el conjunto de circunstancias que al agente policial se presentan evaluándolas como un todo y no una a una, es decir, se descarta examinar cada elemento aisladamente y discerniendo si éste, separado de los demás, constituye o no un indicio de los que trata el artículo 85 CPP.

La CS, en MP c/Sarmiento (2018): 19 diciembre 2018, rol n 26.171-18, explicó que

los hechos ya reproducidos en el basamento cuarto, conforme a las normas que rigen la apreciación de la prueba en este proceso, de lo que se deriva que en esta sede no pueden desconocerse tales hechos, pues de modificarse los mismos se transformaría el recurso de nulidad en una nueva instancia, condición que no se condice con la naturaleza del mismo".

En cuanto a pedir el recurrente que, oyendo extractos de las deposiciones prestadas en el juicio por los policías, la CS establezca hechos diversos a los asentados por los magistrados del grado, el máximo Tribunal, en MP c/Ramos Elgueta (2018, rol n 18.654-18), señaló que "desde que las circunstancias que motivaron el control de identidad y registro al que fue sometido el encartado, fueron materia de prueba y debate en el proceso, es menester estarse a lo asentado por los jueces de la instancia al ponderar las evidencias aportadas a la litis, sin que sea dable que, [...], esta Corte Suprema, con ocasión del estudio de la causal de nulidad propuesta, efectúe una nueva valoración de esas probanzas y fije hechos distintos a los determinados por el tribunal del grado, porque ello quebranta de manera evidente las máximas de oralidad, inmediación y bilateralidad de la audiencia, que rigen la incorporación y valoración de la prueba en este sistema procesal penal, ya que implicaría que este tribunal de nulidad, únicamente de la reproducción parcial de los testimonios rendidos en el juicio-sólo de lo que interesa a la recurrente-, podría dar por acreditados hechos distintos y opuestos a los que los magistrados extrajeron de esas deposiciones, no obstante que estos últimos apreciaron íntegra y directamente su rendición, incluso el examen y contraexamen de los contendientes, así como hicieron las consultas necesarias para aclarar sus dudas, lo que de aceptarse, simplemente transformaría a esta Corte, en lo atinente a los hechos en que se construye esta causal de nulidad, en un tribunal de segunda instancia, lo cual, [...], resulta inaceptable". Así también la CS en MP c/Cabezas (2018, rol $\mathrm{n}^{\circ}$ 6.080-18), MP c/Avendaño (2018, rol n ${ }^{\circ}$ 7.345-18), MP c/Rivera (2018, rol $\mathrm{n}^{\circ}$ 7.516-18), MP c/Pineda (2018, rol no 8.856-18), MP c/Oyarce (2018, rol n 26.182-18) y MP c/Rivera (2019, rol n $\left.{ }^{\circ} 31.242-18\right)$.

Cuando el impugnante ha solicitado que la CS fije hechos diversos a los establecidos en la instancia, en base a las declaraciones de los policías que participan en el control de identidad y conocidas conforme al resumen que de ellas hace la sentencia recurrida, tal petición no ha prosperado, y añade a los razonamientos anteriores la CS, en MP c/Suárez (2018, rol n 8.257-18), que ello "implicaría que este tribunal de nulidad, únicamente de la lectura de los testimonios 'extractados' en la sentencia [...], podría dar por acreditados hechos distintos y opuestos a los que los magistrados extrajeron de esas deposiciones, no obstante que estos últimos apreciaron íntegra y directamente su rendición, incluso el examen y contraexamen de los contendientes, así como hicieron las consultas necesarias para aclarar sus dudas, lo que de aceptarse, simplemente transformaría a esta Corte, en lo atinente a los hechos en que se construye esta causal de nulidad, en un tribunal de segunda instancia, y todavía más, en uno que - a diferencia del a quo-dirime lo factual en base a meras actas o registros [...], lo cual, [...], resulta inaceptable". En igual sentido la CS en MP c/Sánchez (2018, rol $\mathrm{n}^{\circ}$ 19.099-18), MP c/Soto (2018, rol $\mathrm{n}^{\circ}$ 28.126-18), MP c/Cortés (2019, rol $\left.\mathrm{n}^{\circ} 400-19\right)$, MP c/Márquez (2019, rol no 1.502-19), MP c/de la Fuente (2019, rol n².224-19), MP c/González (2019, rol n ${ }^{\circ}$ 2.018-19), MP c/Villalón (2019, rol n ${ }^{\circ}$ 2.865-19), MP c/Quagliuolo (2019, rol $\mathrm{n}^{\circ}$ 7.248-19), MP c/Ávila (2019, rol n $\left.{ }^{\circ} 7.750-19\right)$, MP c/Figueroa (2019, rol n 8.328-19), MP c/Fuentes (2019, rol $\left.\mathrm{n}^{\circ} 9.140-19\right)$ y MP c/Muñoz (2019, rol n 7.756-19). 
"[...] constituye un error [...] analizar si, aisladamente consideradas, cada una de las circunstancias ponderadas por los policías constituían un correlativo indicio de aquellos a que alude el artículo 85 del Código Procesal Penal o, en otras palabras, si cada una de esas circunstancias por sí sola conforma un indicio de que el imputado había cometido un delito o se aprestaba a ello. [...], como se desprende [...] del citado artículo 85 (los policías deberán solicitar la identificación de cualquier persona 'en los casos fundados, en que, según las circunstancias, estimaren que exista algún indicio' de que ella hubiere cometido o intentado cometer un crimen, simple delito o falta), los policías deben discernir si se hallan frente a un caso fundado que justifique el control de identidad de una persona sopesando 'conjuntamente' todas las circunstancias que se presentan o desarrollan ante ellos, a fin de determinar en ese escenario, si de 'todas ellas', globalmente apreciadas, se puede inferir con razonable objetividad que se ha cometido o se va a cometer algún delito por la persona en quien concurren tales circunstancias".

\section{Debe considerarse en este examen las circunstancias percibidas "ex ante" por el policía y que éstas generalmente se presentan intempestivamente}

El escrutinio del cúmulo de circunstancias que se presentan ante el policía, a fin de determinar si ellas dan forma, globalmente valoradas, a algún indicio de actividad delictiva, debe efectuarse mediante una aproximación ex ante sin que tengan relevancia lo ocurrido con posterioridad, sea que confirme o no el indicio que dio lugar al control de identidad ${ }^{23}$.

Bajo la premisa reseñada, la CS, en MP c/Monroy (2018): 11 abril 2018, rol $\mathrm{n}^{\circ} 3.587-18$, expresó que

"[...], relacionando la acción cuestionada con las normas que le son aplicables, resulta posible inferir la legalidad del cometido de los funcionarios policiales. En efecto, las circunstancias objetivas percibidas ex ante por la policía, ciertamente constituían una señal positiva de una probable acción delictiva. Y aun cuando la exigencia legal se satisfaga con un solo indicio, en la especie fueron múltiples: transacción, ocultamiento de especies ante la presencia policial, relato espontáneo del comprador" 24 .

\footnotetext{
${ }^{23}$ Expone FALCONE SALAS (2012) p. 485 que "El control judicial a posteriori, por regla general, debe realizarse desde una perspectiva ex-ante" y precisa CISTERNA (2004) p. 59 que el juez debe colocarse en la posición de un observador imparcial al momento de la detención considerando todos los conocimientos de hecho que tenía el agente al obrar y todos los que le habrían sido razonablemente exigibles.

${ }^{24}$ Misma reflexión la CS en MP c/Alvarado Becerra (2018, rol n $\left.{ }^{\circ} 14.956-18\right)$, MP c/Canio (2018, rol n ${ }^{\circ}$ 13.130-18) y MP c/Cuevas (2019, rol $\mathrm{n}^{\circ}$ 4.282-19). La CS en MP c/Mejías (2019, rol $\left.\mathrm{n}^{\circ} 2.488-19\right)$, a diferencia de antes pero igualmente con una perspectiva ex ante, concluye que no hay indicio de actividad delictiva manifestando que "en la especie se ha esgrimido como fundamento de un control de identidad la circunstancia de haber apreciado el personal policial a un sujeto en un paradero donde un conductor de bus señaló que había dejado a una persona con una mochila que quiso bajarse intempestivamente del vehículo. De ello habría surgido el indicio sobre la presunta actividad delictiva. Sin embargo, tal comportamiento, desde una perspectiva ex ante, carece totalmente de la relevancia asignada, toda vez que en él no se advierten elementos precisos referidos a la comisión de ilícito alguno".
} 
Adoptando esa óptica ex ante no tiene relevancia entonces el devenir posterior al inicio del control de detención y, aún con indicio de un delito y el individuo portando o teniendo ilegalmente un objeto no vinculado al ilícito respecto del cual se presenta el antecedente, nada impide llevar adelante la persecución solo por el delito descubierto en flagrancia o, en su caso, por ambos.

Así, habiendo un indicio de comisión de robo con violencia y hallado con droga el sindicado como autor al controlarse su identidad, la CS, en MP c/Morales (2018): 14 febrero 2018, rol n 44.548-17, declaró que

"la policía actuó habilitada para llevar a cabo el control de identidad, en virtud de la precisa sindicación [...] del imputado como autor del delito de robo con violencia de que fue víctima J.A.R.C., cuya identidad el ofendido logró obtener a través de la red social Facebook, la que dio a conocer a un amigo y a su padre [...]. Como consecuencia de lo anterior, la misma norma los habilitó para proceder a su registro, sin necesidad de contar con nuevos antecedentes o solicitar una orden de detención judicial, produciéndose un hallazgo de droga, lo que permitía su detención inmediata en virtud de la situación de flagrancia constatada, situación que no se ve alterada por el hecho que el control de identidad haya obedecido a una situación diversa, por lo que, como era procedente, el Ministerio Público separó ambas investigaciones, siguiendo cada una su curso regular con las pesquisas propias de cada ilícito indagado".

En este orden de consideraciones, conviene despejar que el actuar policial al controlar identidad se basa solo en un indicio, esto es, en uno o varios antecedentes que dan cuenta, objetivamente, que el afectado "podría" haber cometido, intentado o disponerse a cometer un delito, y no constituye una manifestación clara e inequívoca de tal pues -mencionado at supra- prima que operen las normas de la flagrancia que resulten aplicables según el caso, o sea, el indicio es un elemento "equívoco" ${ }^{25} \mathrm{y}$, por eso, el control de identidad generalmente persigue verificar o descartar la comisión del ilícito, lo que deja espacio, desde luego, para un resultado negativo, lo cual no afectará la validez de la actuación e igual cabe decir si el MP, con los antecedentes derivados del control de identidad, decide no iniciar una investigación o después la abandona.

La CS, en MP c/Rivera (2019): 23 enero 2019, rol n 31.242-18, dispuso que

"no afecta la validez del control de identidad el que posteriormente el delito respecto del cual los policías apreciaron indicios para llevar a cabo ese procedimiento, no sea objeto de persecución por parte del Ministerio Público o de una sentencia condenatoria, pues [...], 'sea que al control de identidad no suceda la investigación y persecución penal de la persona sometida a control, o que iniciada dicha investigación ésta no termine en la sanción penal del imputado, cualquiera de dichas circunstancias no tiene el efecto ipso facto de

\footnotetext{
${ }^{25}$ No obstante la CS, en MP c/Mejías (2019, rol no 2.488-19), parece exigir que se trate de una circunstancia "unívoca", por oposición a una circunstancia o conducta "neutra".
} 
invalidar retroactivamente la diligencia de control [...] si ésta se realizó cumpliendo los presupuestos que el artículo 85 del Código Procesal Penal señala".

Hay que enfatizar que la valoración que debe hacer el tribunal es ex ante porque de no ser así se "permitiría validar un control de identidad sin estándar por la vía de lo que eventualmente se encuentre al sujeto controlado" 26 e implicaría la mecánica validez de todos los controles ya que en casi el total de los sometidos a revisión jurisdiccional se confirma el supuesto indicio por hallarse algún objeto incriminatorio en algún delito (en caso contrario, salvo excepción como orden de detención pendiente, el controlado es dejado en libertad).

Por último, este análisis no omite que las circunstancias que motivan el actuar policial comúnmente son imprevistas y el funcionario en cuanto al control de identidad ha de considerar que si se presenta el indicio que alude el artículo 85 CPP "debe" -y no sólo "puede"-realizarlo, y precisamente la CS, en MP c/Monroy (2018): 11 abril 2018, rol n ${ }^{\circ}$ 3.587-18, destacó que

"es importante razonar sobre el contexto fáctico que usualmente rodea a una diligencia como la de la especie, porque los indicios de la probable comisión de un ilícito se encuentran usualmente en forma intempestiva, situación que obliga a los policías a evaluar de inmediato la presencia de algún elemento susceptible de tal estimación y que haga procedente la actuación,"27.

\section{El control jurisdiccional sobre la legalidad del control de identidad llevado a cabo por las policías sólo busca descartar que se haya efectuado arbitrariamente esa diligencia}

Al dejar la ley al policía apreciar las circunstancias facticas que se le presentan y establecer -sin siquiera consultar a un superior jerárquico o al MP- si está o no ante un indicio de actividad delictiva que lo habilita para controlar identidad -determinación la mayoría de veces realizada en breves momentos y en situaciones confusas y vertiginosas-, es relevante que la CS haya resuelto que el examen posterior que efectúa el órgano jurisdiccional solo pretende verificar que al ponderar y decidir el agente policial ha primado la razón y no la mera arbitrariedad $^{28}$, más allá de si un juez en su lugar habría concluido o no lo mismo ${ }^{29}$.

\footnotetext{
${ }^{26}$ Blanco et al. (2005) p. 55, ROMERO (2007) p. 74 y RABI GONZÁleZ (2010) p. 350.

${ }^{27}$ Resalta el mismo aspecto la CS en MP c/Torres (2017, rol n $\left.{ }^{\circ} 35.167-17\right)$, MP c/Sepúlveda (2017, rol ${ }^{\circ}$ 39.777-17), MP c/Garros (2018, rol n 1.228-18), MP c/Villalba (2018, rol n ${ }^{\circ}$ 1.275-18), MP c/Palma (2018, rol $\mathrm{n}^{\circ}$ 1.279-18), MP c/Vidal (2018, rol n 4.570-18), MP c/Alvarado Becerra (2018, rol $\left.\mathrm{n}^{\circ} 14.956-18\right)$, MP c/Infante (2018, rol n ${ }^{\circ}$ 12.371-18), MP c/Villagra (2018, rol n 18.943-18), MP c/Durán (2019, rol n 5.41319), MP c/Contreras Turri (2019, rol n 8.333-19) y MP c/Vargas (2019, rol n $\left.{ }^{\circ} 9.193-19\right)$.

${ }^{28}$ No debe olvidarse que, como afirman HoRvitz LENNON y LóPEZ MASLE (2003) p. 380, el CPP establece el control de identidad como una forma alternativa a la infame "detención por sospecha", que constituyó en el pasado una fuente profusa de arbitrariedad y discriminación en nuestro país.

${ }^{29}$ RABI GONZÁLEZ (2010) p. 350 señala sobre las circunstancias en que se produce la apreciación original por el policía que "es evidente que ella posee ventajas insuperables propias de la proximidad física entre los agentes de la policía y el sujeto controlado en el entorno que motiva el procedimiento: en ninguna otra oportunidad podrán ser apreciados de manera más certera. En tal sentido, una eventual revisión de mérito posterior debe centrarse en determinar, no tanto si los hechos tenían el carácter de indicio en los términos
} 
Esta línea argumentativa la desarrolla la CS, en MP c/Suárez (2018): 25 junio 2018, rol n 8.257-18, diciendo que

"[...], como el mismo artículo 85 del Código Procesal Penal prescribe, la determinación de la existencia o no de 'algún indicio' debe ser el resultado de una 'estimación' que debe realizar el propio policía 'según las circunstancias', debiendo ocuparse esta Corte únicamente de descartar una actuación arbitraria de los agentes estatales en el desempeño de sus labores preventivas" ${ }^{30}$.

En concordancia con lo anterior, la CS, en MP c/Alvarado Santis (2018): 1 octubre 2018, rol $n^{\circ} 20.606-18$, expone que

"en la situación de autos se presentaba un caso fundado que justificaba efectuar el control de identidad, por concurrir las circunstancias objetivas contempladas en el artículo 85 del Código Procesal Penal, que permiten descartar la arbitrariedad, abuso o sesgo en el actuar policial, objetivo principal al demandarse por la ley la concurrencia de determinados presupuestos para llevar a cabo el control de identidad"31.

Ahondando en estas ideas, cabe precisar que el máximo Tribunal puede no coincidir con la estimación de los funcionarios policiales y justamente, en MP c/Pineda (2018): 3 julio 2018, rol no $8.856-18$, explica que

"Más allá de expresar si esta Corte comparte o no la apreciación de los policías de que en la situación de autos se presentaba un caso fundado que justificaba controlar la identidad de la imputada, lo relevante es que el fallo da por cierta una circunstancia objetiva que admite calificarse como indicio de aquellos a que alude el artículo 85 del Código Procesal Penal, lo que permite descartar la arbitrariedad, abuso o sesgo en el actuar policial, objetivo principal al demandarse por la ley la concurrencia de dicho indicio para llevar a cabo el control de identidad"32.

Como necesaria consecuencia de estos razonamientos, y haciendo más claros aún sus pronunciamientos previos, la CS finalmente refiere que su examen en un recurso de nulidad que ataca la legalidad de un control de identidad no puede asimilarse a uno de segunda instancia, donde la primera instancia correspondería al juicio del propio policía, porque implicaría que los jueces deberían resolver si, amén de cumplirse los requisitos legales para

descritos por el artículo 85 CPP, sino si era razonable y legítimo que los agentes de policía, de buena fe, así lo apreciaran".

${ }^{30}$ Igual razonamiento la CS en MP c/Correa (2018, rol n $\left.{ }^{\circ} 5.353-18\right), M P$ c/Rivera (2018, rol ${ }^{\circ}$ 7.516-18), MP c/Órdenes (2018, rol n $\left.{ }^{\circ} 22.999-18\right)$ y MP c/Rojas (2019, rol n 32.699-18).

${ }^{31}$ Mismas disquisiciones la CS en MP c/Huerta (2019, rol n 31.144-18), MP c/Araos (2019, rol n 4.271-19) y $M P c /$ Santander (2019, rol n $\left.^{\circ} 2.877-19\right)$.

32 También la CS en MP c/Muñoz Plaza (2018, rol n 15.157-18), MP c/Sarmiento (2018, rol n ${ }^{\circ}$ 26.171-18), MP c/Huerta (2019, rol n $\left.{ }^{\circ} 31.144-18\right)$, MP c/Caro (2019, rol n 25-19), MP c/Briceño (2019, rol n ${ }^{\circ} 16.968-$ 18) y $M P c /$ Santander (2019, rol n $\left.^{\circ} 2.877-19\right)$. 
controlar la identidad de una persona, encontrándose en el lugar del funcionario, habrían actuado de igual forma, cuestión esta última que excede dicho control de legalidad.

Así la CS, MP c/Rañileo (2019): 28 junio 2019, rol n 8.339-19, señala que

"como reiteradamente se ha dicho, más allá de expresar si esta Corte comparte o no la apreciación de los policías de que la situación de autos ameritaba controlar la identidad del imputado, desde que no se trata aquí de un examen de segunda instancia recaído sobre la determinación de esos agentes, lo relevante y capital es que el fallo da por ciertas circunstancias que objetivamente y de manera plausible, a un tercero observador imparcial, permitían construir un indicio de aquellos a que alude el artículo $85 \mathrm{del}$ Código Procesal Penal, lo que lleva a descartar la arbitrariedad, abuso o sesgo en el actuar policial, objetivo principal al demandarse por la ley la concurrencia de esa sospecha para llevar a cabo el control de identidad".

Con más precisión, el máximo Tribunal ha indicado que el rol del juez al revisar la legalidad del control de identidad no consiste en sustituir el juicio personal del policía actuante por el propio sino someter el examen de las circunstancias al juicio de un tercer imparcial, concretamente se ha resuelto, en MP c/Peña (2019): 4 junio 2019, rol $\mathrm{n}^{\circ} 8.335-$ 19 , que

"más allá de expresar si esta Corte comparte o no la apreciación de los policías de que la situación de autos ameritaba controlar la identidad de los imputados, desde que no se trata aquí de un examen de segunda instancia sobre la determinación de esos agentes, lo relevante y capital aquí es que el fallo da por ciertas circunstancias que objetivamente y de manera plausible, a un tercero observador imparcial, permitían construir un indicio de aquellos a que alude el artículo 85 del Código Procesal Penal, lo que lleva a descartar la arbitrariedad, abuso o sesgo en el actuar policial, objetivo principal al demandarse por la ley la concurrencia de esa sospecha para llevar a cabo el control de identidad".

\section{CRITERIOS GENERALES PARA DETERMINAR LA EXISTENCIA DE UN INDICIO HABILITANTE PARA EL CONTROL DE IDENTIDAD}

La CS, en el período que comprende este estudio, ha ido perfilando, con mayor o menor consistencia, algunos criterios generales que deben tomarse en cuenta al dirimir si existe algún indicio que permita controlar la identidad a una persona.

\section{Indicio debe presentarse respecto de una o unas personas determinadas}

Desde que el control de identidad afecta a todo individuo a cuyo respecto se presenta un indicio de actividad delictiva -u otra hipótesis del artículo $85 \mathrm{CPP}-$, determinar la persona objeto de tal actuación no es parte del indicio sino un presupuesto indispensable para ejecutarla debiéndose, desde luego, definir quién será controlado por atribuírsele los hechos que conforman el indicio. 
Lo anterior, en términos prácticos, conlleva que si un tercero informa a los policías que en un determinado lugar una persona de particular características (según vestimenta, contextura, etc.) realiza una actividad ilícita ( $v . g r$. , amenaza a peatones, dispara armas de fuego, vende drogas), el mero encuentro de los funcionario policiales en el sitio indicado de alguien con la misma apariencia que expresó el denunciante no constituye un indicio en sí sino un paso previo e indispensable para determinar el individuo al que se atribuye el hecho informado restando entonces que los policías, si no aprecian directamente la conducta a ellos comunicada, reflexionar si la denuncia por sí sola constituye o no un indicio.

El criterio expuesto lo recogió la CS, aunque referido a hechos previos a la Ley $\mathrm{N}^{\circ} 20.931$, en MP c/Gajardo (2016): 10 noviembre 2016, rol n 62.131-16, y es importante tenerlo a la vista porque lo confirma en sentencias posteriores. En esta causa se invocaron dos indicios (pluralidad a la sazón requerida por el artículo $85 \mathrm{CPP}$ ), la denuncia anónima -persona de ciertas características porta arma de fuego por arteria determinada- y "la coincidencia de lo descrito por el denunciante con lo observado por los policías en el denunciado", y no fue discutido

"el que la denuncia anónima pueda calificarse como un indicio de aquellos que demanda el artículo 85 del Código Procesal Penal, ni que dicho indicio requiere de otro adicional para satisfacer los requerimientos de pluralidad de dicho precepto, sino únicamente si la coincidencia de lo descrito por el denunciante con lo observado por los policías en el denunciado, es suficiente para conformar ese otro indicio".

Y sobre el punto sí controvertido que aquí ocupa, se expresó que

"Los indicios a que alude el artículo 85 del Código Procesal Penal, son aquellos elementos objetivos que facultan a los policías para desarrollar las actuaciones que comprende el control de identidad especificadas en esa misma norma -pedir o conseguir la identificación y el registro de quien es objeto del control-, respecto de una persona 'determinada'. [...], los indicios, cualesquiera [...] sean, deben presentarse respecto de personas determinadas, ya sea porque ellas [...] son vistas por los policías realizando una acción $u$ omisión que constituye el indicio, o [...] son sindicadas por otras personas directa o presencialmente, o por referencia a su nombre, apodos, rasgos, etc.que reseñan los hechos que aquéllos habrían ejecutado y que serían constitutivos del indicio, pues únicamente sobre quienes recaigan dichos indicios, la policía podrá restringir transitoriamente su libertad ambulatoria para llevar a cabo el control de identidad"33.

Concluyó la CS que

\footnotetext{
${ }^{33}$ Este párrafo, sin necesariamente querer recalcar los mismos puntos aquí tratados o llegar a iguales conclusiones, la CS lo reproduce posterior a la Ley $\mathrm{N}^{\circ} 20.931$ en $M P$ c/Balbi $\left(2018\right.$, rol n $\left.{ }^{\circ} 7.983-18\right), M P$ c/Campos (2018, rol $\mathrm{n}^{\circ}$ 15.302-18), MP c/Sepúlveda (2018, rol n⿳2 22.000-18), MP c/Piccolini (2018, rol $\mathrm{n}^{\circ}$ 23.312-18), MP c/Romero (2019, rol no 31.238-18), MP c/Contreras (2019, rol no 28.218-18) y MP c/Donoso (2019, rol n²8.219-18).
} 
"cuando se da noticia por un tercero a los policías que un transeúnte porta un arma en la vía pública, y se describe a dicho transeúnte, esto último -la descripción- sólo corresponde al medio indispensable para conectar o atribuir el indicio original -la imputación por un denunciante anónimo del porte del arma en la vía pública- a una persona determinada, pues sin dicha información sobre las características del denunciado, en definitiva el control de identidad no podría concretarse en persona alguna. [...] las características físicas y de vestimenta del imputado, aisladamente examinadas, en caso alguno podrían haber constituido un indicio de la comisión de algún delito, y sólo adquieren relevancia porque permiten enlazar la conducta denunciada a una persona precisa entre todas aquellas que transitaban por el sector referido en la denuncia [...]. [...] la comprobación por los policías de que efectivamente, tal como lo indicó el denunciante anónimo, una persona de las características físicas y que vestía en la forma referida por dicho denunciante, transitaba por la arteria también mencionada por éste, no constituye un indicio complementario a la denuncia misma y, por consiguiente, no se presentaban [...] los supuestos legales que, conforme al artículo 85 del Código Procesal Penal autorizan para llevar a cabo dicha diligencia, esto es [...], un caso fundado, en que, según las circunstancias, los policías estimaren que existen 'indicios' de que la persona sujeta a control hubiere cometido o intentado cometer un crimen, simple delito o falta, contexto en el cual, los policías debieron entonces esperar la ocurrencia o manifestación de otro indicio objetivo que los habilitara para el control de identidad [...], como parte de sus labores preventivas, sin perjuicio de, conforme al artículo 84 del Código Procesal Penal, poner de inmediato en conocimiento del Ministerio Público la denuncia formulada y solicitar de dicho organismo las instrucciones pertinentes al caso y, al no haber actuado así, los agentes estatales obraron en contravención a la ley, vulnerando en definitiva el derecho del acusado de autos al debido proceso, en cuanto por éste se garantiza el derecho a una investigación racional y justa”.

Ahora bien, destaco que estas reflexiones tuvieron aplicación y efectos sustanciales en casos bajo el artículo 85 CPP no modicado aún por la Ley $\mathrm{N}^{\circ} 20.931$, en que se requería conforme interpretó la CS (como en MP c/Gajardo (2016): 10 noviembre 2016, rol $\mathrm{n}^{\circ}$ 62.131-16) - pluralidad de indicios, lo cual acarrea que meramente coincidir en ubicación y características el sindicado que informa el denunciante y la persona controlada no constituyen indicio y, en consecuencia, no queda más que la denuncia misma, en general anónima, la que, dada su singularidad, no satisface el requisito de ser dos o más los indicios para efectuar el control de identidad.

\section{No es necesario que los hechos o circunstancias que conforman el indicio sean observados directamente por el policía}

La CS en un principio resolvió contrario a lo indicado en el epígrafe y, en $M P$ c/Valencia (2017): 13 septiembre 2017, rol no 36.630-17, denunciado que en un lugar determinado dos sujetos a bordo de un vehículo del que también se entregaron todos los antecedentes 
estaban cometiendo un delito de tráfico de estupefacientes", declaró que no existe indicio si no hay una "apreciación directa por parte de los funcionarios".

Y es más, el fallo en cuestión sobre la circunstancia venta de droga agregó que

"los funcionarios obraron sin haber constatado personalmente ninguna conducta constitutiva del indicio que el artículo 85 contempla como requisito para validar la actuación autónoma de las policías [...] no obstante lo cual realizaron la diligencia aludida [...]. [...], [...] que exista un relato referido a que sujetos a bordo de un vehículo determinado comercializaban droga en un lugar en concreto constituye un antecedente suficiente para que la policía concurra al lugar en cumplimiento de las obligaciones que le impone la ley. Sin embargo, tal comunicación [...] se agota en su propia formulación, de manera que al faltar su constatación mediante la apreciación directa por parte de los funcionarios o de un tercero ajeno a la diligencia de algún acto que confirme lo comunicado a la unidad policial -venta de droga por los ocupantes del móvilno existe el indicio que exige el artículo 85 del Código Procesal Penal para validar su proceder [...]. [...], los agentes policiales poseen únicamente la denuncia antes referida que se confirma sólo en la parte de la presencia del vehículo descrito, lo que no constituye en forma alguna un signo que permita sospechar la comisión de un delito - sea ya cometido o por cometer-al dar cuenta únicamente de la mera materialidad de la presencia de los imputados en el lugar" 34 .

Al respecto, si los agentes policiales vieron que los ocupantes del móvil vendían droga, y conforme disponen los artículos 129 y 130 a) CPP, tenían el "deber" de proceder a la detención por tratarse de una situación de flagrancia, de manera que mediante la exigencia de apreciación directa por los policías que levanta la CS se equipara, equivocadamente creo, el indicio a la antedicha situación y deja sin ámbito de aplicación efectiva al artículo 85.

\footnotetext{
${ }^{34}$ Vuelve más adelante a este criterio la CS en MP c/Miranda (2018, rol $\left.\mathrm{n}^{\circ} 26.422-18\right)$ al reiterar que los policías deben apreciar directamente algún elemento o indicio que ratifique o avale lo denunciado de manera anónima, siendo entonces insuficiente encontrar a una persona de las mismas características y en el mismo lugar referido en la denuncia. En ese orden señala el fallo que "en la especie se ha esgrimido como fundamento de un control de identidad [...] haber apreciado el personal policial a un sujeto cuyas características físicas y de vestimenta les fueron proporcionadas por un denunciante anónimo, el que, según el parecer del denunciante se encontraba vendiendo droga [...], [...]. De ello habría surgido el indicio sobre la presunta actividad delictiva. Sin embargo, tal comportamiento, desde una perspectiva ex ante, carece de la relevancia asignada, toda vez que en él no se advierten elementos precisos referidos a la comisión de ilícito alguno [...]. [...], [....], lo que motiva la presencia policial en el lugar de la detención es la ya citada denuncia anónima dando cuenta de la presencia de un sujeto que estaría vendiendo drogas en una ubicación determinada, lo que no fue constatado por los policías al constituirse en el lugar, de manera que lo efectivamente observado por ellos -un sujeto en la vía pública-configura por esencia una conducta absolutamente neutra, no sólo tolerada, sino que tutelada por el ordenamiento jurídico, desde que la libertad ambulatoria es un derecho de todo habitante de la República, susceptible de ser ejercido y protegido, por lo que esta circunstancia dista de satisfacer los presupuestos que exige el artículo 85 del Código Procesal Penal para realizar el control de identidad".
} 
Hay sí situaciones de flagrancia en el artículo 130 CPP que no requieren que el policía "aprecie directamente" la actividad delictiva que un tercero atribuye a otro y que permiten la detención de éste y tal sindicación, cumpliendo los requisitos de la norma en comento, impone al policía la aprehension, de manera que no podría demandarse para el control de identidad, que importa una limitación de mucho menor intensidad a la libertad ambulatoria que la detención, mayores condiciones y requisitos para su materialización.

Del modo antedicho se expresó la CS, en MP c/Amaya (2015): 11 junio 2015, rol n 5.841 15 , pronunciamiento anterior a la Ley $\mathrm{N}^{\circ} 20.931$, pues manifesto que

"en el entendido de que existió una denuncia anónima que entregaba información precisa sobre los autores de un delito de tráfico de drogas en actual ejecución, resulta irrelevante que los funcionarios policiales no hayan presenciado u observado de manera directa alguna conducta de los propios acusados que pudiera constituir un indicio de aquellos que enuncia el artículo 85 del Código Procesal Penal y que autorizan para realizar la diligencia de control de identidad, pues la norma mencionada no contiene expresamente dicha exigencia ni tampoco es posible desprenderla de una correcta interpretación sistemática de las disposiciones que regulan actuaciones autónomas de las policies [...]. [...], si se limitase la diligencia de control de identidad sólo a aquellos supuestos en que los funcionarios policiales advirtieran directa e inmediatamente alguna 'conducta objetiva' que pudiese llevarlos a estimar que la persona que se someterá a la actuación policial está cometiendo o ha cometido un delito [...], ello importaría que la diligencia de control de identidad demandaría mayores requisitos, o estándares más rigurosos, que la propia detención en situación de flagrancia, pues la letra e) del artículo 130 del Código Procesal Penal autoriza dicha privación temporal de libertad ambulatoria del 'que las víctimas de un delito que reclamen auxilio, o testigos presenciales, señalaren como autor o cómplice de un delito que se hubiere cometido en un tiempo inmediato', caso en el cual quien realiza la detención no aprecia directamente ninguna acción o comportamiento con carácter delictivo por parte de quien es sindicado como autor o cómplice de un ilícito, pues es la sindicación de un tercero -la víctima o el testigo presencialla que justifica y valida la detención"

Coincidente con estas reflexiones, en el lapso objeto de este estudio, la CS, en $M P$ c/Avendaño Inzunza (2018): 1 agosto 2018, rol n 13.142-18, resolvió que "lo que la norma del artículo 85 del Código del ramo exige no es la percepción por medio de los sentidos de una conducta delictiva, sino la existencia de indicios (señas, síntomas, asomos) de su ocurrencia, de manera que su aquilatamiento queda entregado al personal actuante, sin perjuicio del control ex post que corresponde a la judicatura"36.

\section{La experiencia y el conocimiento que poseen los policías sobre las características de}

\footnotetext{
${ }^{35}$ Razonamiento reiterado por la CS en MP c/Carrasco $\left(2016\right.$, rol n $\left.{ }^{\circ} 5.363-16\right)$ y $M P$ c/Hidalgo $\left(2016\right.$, rol $\mathrm{n}^{\circ}$ 2.656-16), ambos procesos sobre hechos anteriores a la Ley $\mathrm{N}^{\circ} 20.931$.

${ }^{36}$ Igual disquisición la CS en MP c/Muñoz Plaza (2018, rol n 15.157-18).
} 


\section{los lugares en los que desarrollan su labor preventiva debe ser considerado al dirimir judicialmente la existencia del indicio}

Este enunciado surge de dictaminar la CS, en MP c/Villarreal (2017): 13 septiembre 2017, rol $\mathrm{n}^{\mathrm{o}} 36.237-17$, observado por los policías que se intercambia dinero por un envoltorio "en un sector conocido -entre otros aspectos- por su conflictividad vinculada al comercio de droga", que

"el indicio constatado -que en una primera mirada podría ser mínimo y absolutamente neutral- se complementa necesariamente con la experiencia que posee quien lo advierte, dotándolo de un significado que compele a los funcionarios a actuar en cumplimiento de sus obligaciones [...]. En tales condiciones, [...], sólo resta concluir que es lícito el proceder policial que, analizando las conductas de los ciudadanos bajo el prisma de su experiencia y el conocimiento que poseen sobre las características de los lugares en los que desarrollan su labor preventiva, estiman acertadamente que el intercambio de objetos de pequeño tamaño entre dos sujetos [...] resulta un indicio con la entidad suficiente para provocar su actuación autónoma en el marco del control de identidad consagrado en el artículo 85 del Código Procesal Penal ${ }^{37}$.

Este pronunciamiento toca un aspecto problemático porque atañe a conductas que ordinariamente se considerarían -usando los propios adjetivos de la CS- "neutras" y, por ende, no indiciarias de un propósito delictivo, y el realizarse en un sector que los policías catalogan -justificadamente o no- como uno en que reiteradamente se denuncia o comete un determinado tipo de ilícitos -piénsese en una plaza pública- importaría continuamente controlar la identidad a toda persona que por el sector habitualmente transita o ahí vive o trabaja, en definitiva, solo por morar o desarrollar su actividad cotidiana en el lugar, lo que es totalmente discriminatorio pues circular, residir o laborar en otra zona los agentes policiales estimarían cada situación ser neutra, o sea, en un caso como el resuelto, entregar un envoltorio pequeño a cambio de dinero y control a mujer que "se dedicaba al comercio de pescado" mientras ejercía ese comercio, de haber el comportamiento acontecido en otro punto de la ciudad, como una feria artesanal en plaza de comuna con menos denuncias o perpetración de un mismo delito, no habría motivo para efectuar el control de identidad e imponiendo las cargas inherentes a esta diligencia ${ }^{38}$.

\footnotetext{
${ }^{37}$ La CS en MP c/Pacheco (2018, rol $\mathrm{n}^{\circ}$ 24.659-18), acudiendo a las mismas consideraciones arriba reproducidas, declara que "el conocimiento que poseen [los policías] sobre las características de los lugares en los que desarrollan su labor preventiva" puede llevar a considerar "el movimiento de manos en un grupo indeterminado de individuos" como un indicio de actividad delictiva.

${ }^{38} \mathrm{La}$ CS en MP c/Reyes Arias (2018, rol n ${ }^{\circ} 10.625-18$ ), observando los funcionario policiales únicamente que una persona sentada en un banco de una plaza pública "realizaba movimientos atribuibles a comercialización de droga", señala que esta conducta adquiere relevancia porque "existían antecedentes que en ese lugar se dedicaban a la comercialización de droga", es decir, los que ocupen o disfruten de esa plaza -menores de edad, adulto mayor, etc.- estarían obligados a soportar continuamente las cargas que implica el control de identidad no obstante desplegar conductas neutras y cotidianas, y únicamente debido a que se trata de un sector respecto del cual hay denuncias de la comisión reiterada de un determinado tipo de delitos, carga no impuesta a los habitantes de otro sector de la ciudad. Sobre los problemas que puede plantear el control de identidad para la justicia social en el espacio público, vid. IRARRÁZABAL (2015) p. 256.
} 
Aunque mis reflexiones no constituyen expresamente fundamento de lo decidido por la CS, en MP c/Pavez (2017): 15 junio 2017, rol no 15.472-17, sí se advierte una aplicación material de las mismas.

En efecto, en el caso en cuestión uno de los indicios que apreció el TJOP es que el imputado está en la cercanía inmediata de un grupo de personas pesquisadas en un procedimiento de drogas efectuado por agentes de una Brigada especializada "en un lugar público, que según la experiencia policial que detentan, reconocen como lugar frecuente y común de la actividad de tráfico ilícito de estupefacientes” y sobre ello la CS expresó que

"haber sorprendido a un tercero efectuando una transacción de droga, en un lugar que es conocido por dicha actividad, mero antecedente singular que, aunque sea corroborado, dista de satisfacer el estándar que impone el artículo 85 citado ya que no constituye en forma alguna un signo que permita sospechar la comisión de un delito -sea ya cometido o por cometer-así como tampoco la mera materialidad de la presencia del acusado en el lugar -único elemento indubitadamente probado- que permite colegir la concurrencia de alguna de las restantes situaciones que el artículo 85 considera para permitir el control aludido".

La CS explica además que "[...] el acusado de manera lenta, pero asertiva camine retirándose en el marco de esa acción policial, es un acto normal, del ejercicio de un derecho consistente en encontrarse en un lugar y trasladarse a otro, [...] además que estaba en las inmediaciones de su domicilio, [...] ]ello no puede constituir un indicio basado en un caso fundado", lo que se relaciona con lo antes discurrido pues, de otra manera, significaría que todo usuario de esa plaza con domicilio alrededor de ella se vería sometido sistemáticamente a las cargas del control de identidad únicamente por utilizar ese espacio público, el que también frecuentan terceros para actividades delictivas que no están en sus manos reprimir ni controlar.

\section{Los hechos que conforman el indicio no pueden ser vagos y amplios, y el indicio debe ser serio y verosímil}

En diversos fallos la CS ha resuelto que la "vaguedad y amplitud" de los "hechos" invocados para justificar el control de identidad impide considerarlos como un indicio al efecto, por ejemplo, el que un copiloto en un control vehicular baje la vista o trate de ocultar su cara se estimó, en MP c/Piccolini (2018): 10 diciembre 2018, rol no 23.312-18, que son hechos que

"dado su vaguedad y amplitud, no pueden constituir indicios de la comisión de un crimen, simple delito o falta por una persona determinada, que permitan efectuarlo [...]. En efecto, los policías, en sus declaraciones extractadas en la sentencia, no refieren ningún elemento o circunstancia-amén de haber bajado la vista o tratar de ocultar su rostro en la camisa- que permitiera practicar la diligencia pues [...] no ven al acusado portar algún elemento u objeto que permitiera sospechar que él hubiese cometido o intentado cometer algún tipo de falta, crimen o simple delito, ni menos que haya efectuado alguna acción 
indiciaria de lo mismo. Las circunstancias invocadas por los funcionarios aprehensores [...] no resultan un indicio 'objetivo' de actividad delictiva, pues puede obedecer a múltiples razones legítimas e inocuas, constituyendo la suposición contraria sólo una impresión o interpretación, sesgada y parcial, subjetividad que, por consiguiente, no puede servir de sostén para una restricción de los derechos de las personas por parte de agentes del Estado" "39.

Finalmente, la CS enfatiza que el indicio debe ser "serio y verosímil", así, en MP c/Sobarzo (2019): 22 de mayo de 2019, rol n 9.194-19, expone que

${ }^{39}$ Este planteamiento en el máximo Tribunal es constante, y con fallo del a quo que declara indicio "[...] que el acusado, [...], al ver la presencia de los funcionarios policiales guardó algo en la pretina de su pantalón, razón por la cual fue requerido para realizarle el control de identidad y [...] en ese momento [...] procedieron a registrar sus vestimentas, encontrando las municiones y el arma corto punzante [....", la CS, en MP c/Romero (2019, rol no 31.238-18), resolvió que "los hechos descritos [...], [...], dada su vaguedad y amplitud, no pueden constituir indicios de la comisión de un crimen, simple delito o falta por una persona determinada, o de que permitan efectuarlo. [...], los policías, [...], no refieren ningún elemento o circunstancia -amén de haber guardado algo en la pretina de su pantalón-, [...] no ven al acusado portar algún elemento u objeto que permitiera sospechar que él hubiese cometido o intentado cometer algún tipo de falta, crimen o simple delito, ni [...] alguna acción indiciaria de lo mismo. Las circunstancias invocadas por los [...] aprehensores [...] no resultan un indicio 'objetivo' de actividad delictiva, pues puede obedecer a múltiples razones legítimas e inocuas, constituyendo la suposición contraria sólo una impresión o interpretación, sesgada y parcial, subjetividad que, por consiguiente, no puede servir de sostén para una restricción de [...] derechos de las personas por [...] agentes del Estado". Considerando la sentencia impugnada indicios "[...] que el acusado se haya encontrado, tanto de forma temporal como espacial, cerca del lugar de los hechos y, que al haber advertido la presencia policial, haya emprendido la huida", la CS, en MP c/Contreras (2019, rol $\mathrm{n}^{\mathrm{o}}$ 28.218-18), estableció que esos hechos "dada su vaguedad y amplitud, no pueden constituir indicios de la comisión de un crimen, simple delito o falta por una persona determinada, [...]. [...], los policías, en sus declaraciones extractadas en la sentencia, no refieren ningún elemento o circunstancia -amén de haberse encontrado el imputado cerca del lugar de los hechos, junto a una proximidad temporal, para luego huir al advertir la presencia policial- [...], [...] los policías no ven al acusado portar algún elemento u objeto que permitiera sospechar que él hubiese cometido o intentado cometer algún tipo de crimen, simple delito o falta, ni [...] alguna acción indiciaria de lo mismo. Las circunstancias invocadas por los [...] aprehensores [...] no resultan un indicio 'objetivo' de actividad delictiva, pues puede obedecer a múltiples razones legítimas e inocuas, constituyendo la suposición contraria sólo una impresión o interpretación, sesgada y parcial, subjetividad que, por consiguiente, no puede servir [...] para [...] restricción de [...] derechos de las personas por [...] agentes del Estado. (SCS Roles 41.34217, de 7 de noviembre de 2017; 6.067-18, de 27 de mayo de 2018; 7.513-18, de 11 de junio de 2018; 15.14818, de 11 de septiembre de 2018; y, 23.312-18 de 10 de diciembre de 2018)". Precisando el Tribunal del grado que "considera como indicio, separar las manos y guardar 'algo' en una mochila, circunstancia que habría motivado a los agentes policiales para efectuar un control de identidad y efectuar un registro en las pertenencias del imputado", la CS, en MP c/Donoso (2019, rol n $\left.{ }^{\circ} 28.219-18\right)$, estimó que estos hechos "no pueden constituir indicios de la comisión de un crimen, simple delito o falta por una persona determinada, [...]. [...], los policías, en sus declaraciones extractadas en la sentencia y en los registros de audio [...], no refieren ningún elemento o circunstancia -amén de haber separado las manos, de haberse mirado o el haber guardado algo en una mochila-, [...] no ven al acusado portar algún elemento u objeto que permitiera sospechar que él hubiese cometido o intentado cometer algún tipo de crimen, simple delito o falta, ni [...] alguna acción indiciaria de lo mismo. Las circunstancias invocadas por los [...] aprehensores [...] no resultan un indicio 'objetivo' de actividad delictiva, pues pueden obedecer a múltiples razones legítimas e inocuas, constituyendo la suposición contraria sólo una impresión o interpretación, sesgada y parcial, subjetividad que, por consiguiente, no puede servir de sostén para una restricción de los derechos de las personas por parte de agentes del Estado." 
"existieron una serie de antecedentes que apreciados en su conjunto, hacían plausible el control policial. El hecho de que al enfrentarse a los funcionarios policiales dejaran en la vía pública los balones de gas que portaban y huyeran daban plena legitimidad a la actuación realizada, permitiéndoles así, restringir la libertad ambulatoria de los acusados, así como dar con los medios de comprobación del delito, llegando en definitiva al domicilio de la víctima, quien dio cuenta de la sustracción de las especies objeto del delito. Lo anterior, desde que existía más de un indicio de carácter serio y verosímil ${ }^{, 40}$.

\section{BIBLIOGRAFÍA CITADA}

AldunAtE, Eduardo (2008): Derechos fundamentales (Santiago de Chile, LegalPublishing).

Blanco, Rafael et al. (2005): Litigación Estratégica en el Nuevo Proceso Penal (Santiago de Chile, Lexis Nexis).

CISTERNA, Adolfo (2004): La detención por flagrancia en el nuevo proceso penal (Santiago de Chile, Librotecnia).

DuCE, Mauricio y RIEGO, Cristián (2009): Proceso Penal (Santiago de Chile, Editorial Jurídica de Chile).

FALCONE SALAS, Diego (2012): "Concepto y sistematización de la detención ilegal en el proceso penal chileno", Revista de Derecho de la Pontificia Universidad Católica de Valparaíso, vol. 38, $\mathrm{n}^{\circ}$ 1, pp. 433-495. Disponible en: http://www.rdpucv.cl/index.php/rderecho/article/view/819/761, fecha de consulta: 4 de junio de 2019.

Horvitz Lennon, María Inés y LóPez Masle, Julián (2003): Derecho Procesal Penal Chileno. T. I $\left(1^{\mathrm{a}}\right.$ reimpresión de $1^{\mathrm{a}}$ ed. 2002, Santiago de Chile, Editorial Jurídica de Chile).

IrarRázabal, Paz (2015): "Igualdad en las calles en Chile: el caso del control de identidad", Polít. crim, vol. 10, $\mathrm{n}^{\mathrm{o}}$ 19, pp. 234-265. Disponible en: http://www.politicacriminal.cl/Vol_10/n_19/Vol10N19A8.pdf, fecha de consulta: 5 de junio de 2019.

LóPeZ Masle, Julián (2004): "La Prueba”, en Horvitz Lennon, María Inés y LóPeZ MasLe, Julián, Derecho Procesal Penal Chileno. T. II (Santiago de Chile, Editorial Jurídica de Chile), pp. 65-228.

\footnotetext{
${ }^{40} \mathrm{La}$ CS, en MP c/Contreras Turri (2019, rol n $\left.{ }^{\circ} 8.333-19\right)$, destaca que las circunstancias observadas por los policías deben revestir "seriedad y verosimilitud" al señalar "Que relacionando la acción cuestionada con las normas que le son aplicables, resulta simple inferir la legalidad del cometido de los funcionarios policiales, quienes observaron circunstancias que revestían seriedad y verosimilitud-dada la dinámica descrita-para inferir que los individuos se aprestaban a cometer un delito de violación de morada o de robo en lugar habitado". Resalta las mismas condiciones la CS en MP c/Vargas (2019, rol n 9.193-19).
} 
RABI GOnZÁlEZ, Roberto (2010): "Qué rol y justificación tiene el control de identidad de una persona en nuestro sistema procesal penal, considerando el actual texto del artículo 85 del Código Procesal Penal?", Revista de Estudios de la Justicia, $\mathrm{n}^{\circ}$ 13, pp. 323-363. Disponible en: https://rej.uchile.cl/index.php/RECEJ/article/view/28538/30295, fecha de consulta: 10 de junio de 2019.

Romero, Rubén (2007): Control de Identidad y Detención (2 $2^{\mathrm{a}}$ ed., Santiago de Chile, Librotecnia)

\section{NORMAS JURÍDICAS CITADAS}

Ley N 19.640, de 15 de octubre de 1999, Ley Orgánica Constitucional del Ministerio Público.

Ley N 19.696, de 12 de octubre de 2000, Establece Código Procesal Penal.

Ley $\mathrm{N}^{\circ}$ 20.253, de 14 de marzo de 2008, modifica el Código Penal y el Código Procesal Penal en materia de seguridad ciudadana, y refuerza las atribuciones preventivas de las policías.

Ley $\mathrm{N}^{\circ}$ 20.931, de 5 de julio de 2016, facilita la aplicación efectiva de las penas establecidas para los delitos de robo, hurto y receptación y mejora la persecución penal en dichos delitos.

\section{JURISPRUDENCIA CITADA}

CS, MP c/Inzunza (2014), 19 de junio de 2014, rol n 8.644-14

CS, MP c/Amaya (2015): 11 de junio de 2015, rol n 5.841-15

CS, MP c/Carrasco (2016): 3 de marzo de 2016, rol n 5.363-16

CS, MP c/Hidalgo (2016): 15 de marzo de 2016, rol n 2.656-16

CS, MP c/Gajardo (2016): 10 de noviembre de 2016, rol n 62.131-16

CS, MP c/Pavez (2017): 15 de junio de 2017, rol n' 15.472-17

CS, MP c/Cifuentes (2017): 22 de junio de 2017, rol n 19.113-17

CS, MP c/Torres (2017), 23 de agosto de 2017, rol n ${ }^{\circ} 35.167-17$

CS, MP c/Villarreal (2017): 13 de septiembre de 2017, rol no 36.237-17

CS, MP c/Valencia (2017): 13 de septiembre de 2017, rol no 36.630-17 
CS, MP c/Sepúlveda (2017): 22 de noviembre de 2017, rol n 39.777-17

CS, MP c/Llancaleo (2017): 21 de diciembre de 2017, rol n 37.208-17

CS, MP c/Ramírez (2018): 30 de enero de 2018, rol n 44.457-17

CS, MP c/Morales (2018): 14 de febrero de 2018, rol n 44.548-17

CS, MP c/Garros (2018): 28 de febrero de 2018, rol n $1.228-18$

CS, MP c/Villalba (2018): 7 de marzo de 2018, rol n 1.275-18

CS, MP c/Palma (2018): 14 de marzo de 2018, rol n 1.279-18

CS, MP c/Herrera (2018): 26 de marzo de 2018, rol n $2.519-18$

CS, MP c/Monroy (2018): 11 de abril de 2018, rol n 3.587-18

CS, MP c/Vidal (2018): 26 de abril de 2018, rol n $4.570-18$

CS, MP c/Correa (2018): 7 de mayo de 2018, rol n 5.353-18

CS, MP c/Cabezas (2018): 22 de mayo de 2018, rol n ${ }^{\circ}$ 6.080-18

CS, MP c/Rojas (2018): 23 de mayo de 2018, rol n 6.345-18

CS, MP c/Avendaño (2018): 28 de mayo de 2018, rol n 7.345-18

CS, MP c/Rivera (2018): 18 de junio de 2018, rol n $7.516-18$

CS, MP c/Balbi (2018): 19 de junio de 2018, rol no 7.983-18

CS, MP c/Marambio (2018): 19 de junio de 2018, rol n 7.575-18

CS, MP c/Suárez (2018): 25 de junio de 2018, rol nº 8.257-18

CS, MP c/Pineda (2018): 3 de Julio de 2018, rol no 8.856-18

CS, MP c/Muñoz Quilempan (2018): 5 de julio de 2018, rol no 8.255-18

CS, MP c/Igor (2018): 5 de julio de 2018, rol n $8.258-18$

CS, MP c/Reyes Arias (2018): 26 de julio de 2018, rol n ${ }^{\circ} 10.625-18$

CS, MP c/Avendaño Inzunza (2018): 1 de agosto de 2018, rol n 13.142-18

CS, MP c/Canio (2018): 6 de agosto de 2018, rol n 13.130-18 
CS, MP c/Alvarado Becerra (2018): 6 de agosto de 2018, rol n 14.956-18

CS, MP c/Muñoz Plaza (2018): 8 de agosto de 2018, rol n ${ }^{\circ}$ 15.157-18

CS, MP c/Infante (2018): 21 de agosto de 2018, rol n 12.371-18

CS, MP c/Campos (2018): 27 de agosto de 2018, rol n 15.302-18

CS, MP c/Sánchez (2018): 24 de septiembre de 2018, rol n¹9.099-18

CS, MP c/Ramos Elgueta (2018): 26 de septiembre de 2018, rol n ${ }^{\circ} 18.654-18$

CS, MP c/Villagra (2018): 26 de septiembre de 2018, rol $\mathrm{n}^{\circ} 18.943-18$

CS, MP c/Alvarado Santis (2018): 1 de octubre de 2018, rol n ${ }^{\circ} 20.606-18$

CS, MP c/Sepúlveda (2018): 22 de octubre de 2018, rol nº 22.000-18

CS, MP c/Órdenes (2018): 30 de octubre de 2018, rol no 22.999-18

CS, MP c/Pacheco (2018): 28 de noviembre de 2018, rol no 24.659-18

CS, MP c/Murillo (2018): 29 de noviembre de 2018, rol no 26.194-18

CS, MP c/Miranda (2018): 6 de diciembre de 2018, rol n 26.422-18

CS, MP c/Piccolini (2018): 10 de diciembre de 2018, rol n 23.312-18

CS, MP c/Soto (2018): 13 de diciembre de 2018, rol n ${ }^{\circ} 28.126-18$

CS, MP c/Sarmiento (2018): 19 de diciembre de 2018, rol n ${ }^{\circ} 26.171-18$

CS, MP c/Oyarce (2018): 26 de diciembre de 2018, rol n 26.182-18

CS, MP c/Villanueva (2018): 26 de diciembre de 2018, rol ${ }^{\circ}$ 26.724-18

CS, MP c/Burgos (2019): 23 de enero de 2019, rol n 28.309-18

CS, MP c/Romero (2019): 23 de enero de 2019, rol no 31.238-18

CS, MP c/Rivera (2019): 23 de enero de 2019, rol n 31.242-18

CS, MP c/Huerta (2019): 29 enero 2019, rol n³ 31.144-18

CS, MP c/Contreras (2019): 4 de febrero de 2019, rol no 28.218-18

CS, MP c/Donoso (2019): 4 de febrero de 2019, rol n $28.219-18$ 
CS, MP c/Caro (2019): 12 de febrero de 2019, rol n 25-19

CS, MP c/Rojas (2019): 13 de febrero de 2019, rol n $32.699-18$

CS, MP c/Briceño (2019): 26 de febrero de 2019, rol nº 16.968-18

CS, MP c/Cortés (2019): 28 de febrero de 2019, rol n 400-19

CS, MP c/Márquez (2019): 28 de febrero de 2019, rol nº 1.502-19

CS, MP c/Torres (2019): 28 de febrero de 2019, rol no 2.222-19

CS, MP c/Mejías (2019): 28 de febrero de 2019, rol nº 2.488-19

CS, MP c/de la Fuente (2019): 7 de marzo de 2019, rol n 2.224-19

CS, MP c/González (2019): 21 de marzo de 2019, rol n² 2.018-19

CS, MP c/Araos (2019): 25 de marzo de 2019, rol n 4.271-19

CS, MP c/Cuevas (2019): 27 de marzo de 2019, rol n 4.282-19

CS, MP c/Villalón (2019): 28 de marzo de 2019, rol n$^{\circ} 2.865-19$

CS, MP c/Santander (2019): 2 de abril de 2019, rol n 2.877-19

CS, MP c/Durán (2019): 8 de abril de 2019, rol n 5.413-19

CS, MP c/González Girón (2019): 10 de abril de 2019, rol nº 5.419-19

CS, MP c/Quagliuolo (2019): 6 de mayo de 2019, rol n 7.248-19

CS, MP c/Ávila (2019): 9 de mayo de 2019, rol n 7.750-19

CS, MP c/Contreras Turri (2019): 13 de mayo de 2019, rol n ${ }^{\circ} 8.333-19$

CS, MP c/Figueroa (2019): 16 de mayo de 2019, rol n ${ }^{\circ} 8.328-19$

CS, MP c/Vargas (2019): 20 de mayo de 2019, rol n 9.193-19

CS, MP c/Sobarzo (2019): 22 de mayo de 2019, rol n 9.194-19

CS, MP c/Dorado (2019): 29 de mayo de 2019, rol n 9.773-19

CS, MP c/Fuentes (2019): 3 de junio de 2019, rol n $9.140-19$

CS, MP c/Peña (2019): 4 de junio de 2019, rol n $8.335-19$ 
CS, MP c/Muñoz (2019): 5 de junio de 2019, rol n ${ }^{\circ} 7.756-19$

CS, MP c/González Rincón (2019): 26 de junio de 2019, rol n 12.166-19

CS, MP c/Rañileo (2019): 28 de junio de 2019, rol n 8.339-19

CAp Santiago, MP c/Villarroel (2018): 21 de agosto de 2018, rol n 41.68-18

Octavo JG Santiago, MP c/Rañileo (2019), 15 de marzo de 2019, RUC N ${ }^{\circ} 1800614688-7$ y RIT N 4936-2018 